\title{
REFINED HEINZ OPERATOR INEQUALITIES AND NORM INEQUALITIES
}

\author{
A. G. GHAZANFARI
}

Abstract. In this article we study the Heinz and Hermite-Hadamard inequalities. We derive the whole series of refinements of these inequalities involving unitarily invariant norms, which improve some recent results, known from the literature.

We also prove that if $A, B, X \in M_{n}(\mathbb{C})$ such that $A$ and $B$ are positive definite and $f$ is an operator monotone function on $(0, \infty)$. Then

$$
\left\||| f(A) X-X f(B)\left|\left\|\left|\leqslant \max \left\{\left\|f^{\prime}(A)\right\|, \| f^{\prime}(B)||\right\}\right|\right\| A X-X B\right|\right\| .
$$

Finally we obtain a series of refinements of the Heinz operator inequalities, which were proved by Kittaneh and Krnić.

Mathematics subject classification (2010): 47A30, 47A63, 15A45.

Keywords and phrases: Norm inequality, operator inequality, Heinz mean.

\section{REFERENCES}

[1] I. Ali, H. Yang AND A. Shakoor, Refinements of the Heron and Heinz means inequalities for matrices, J. Math. Inequal. 1 (2014), 107-112.

[2] R. BHATIA, Interpolating the arithmetric mean inequality and its operator version, Linear Algebra Appl. 413 (2006), 355-363.

[3] R. Bhatia, Matrix analysis, Springer-Verlag, New York, 1997.

[4] R. BhatiA, C. Davis, A Cauchy-Schwarz inequality for operators with applications, Linear Algebra Appl. 223/224 (1995) 119-129.

[5] D. DRISSI, Sharp inequalities for some operator means, J. Matrix Anal. Appl. 28 (2006), 822-828.

[6] Y. Kapil, C. Conde, M. S. Moslehian, M. Singh, M. Sababheh, Norm Inequalities Related to the Heron and Heinz Means, Mediterr. J. Math. (2017), 14:213.

[7] Y. KAPIL, M. SINGH, Contractive maps on operator ideals and norm inequalities, Linear Algebra Appl. 459 (2014), 475-492.

[8] R. KaUR, M. Singh, Complete interpolation of matrix version of Heron and Heinz means, J. Math. inequal., 16, 1 (2013), 93-99.

[9] R. Kaur, M. Sal Moslehian, M. Singh, C. Conde, Further refinements of the Heinz inequality, Linear Algebra and its Applications 447 (2014) 26-37.

[10] F. KitTaneh, On the convexity of the Heinz means, Integr. Equ. Oper. Theory 68 (2010), 519-527.

[11] F. Kittaneh And M. KRnić, Refined Heinz operator inequalities, Linear and Multilinear Algebra, 61 (8) (2013), 1148-1157.

[12] F. Kubo, T. Ando, Means of positive linear operators, Math. Ann. 246 (1980) 205-224.

[13] G. Larotonda, Norm inequalities in operator ideals, J. Funct. Anal. 255 (2008) 3208-3228.

[14] J. E. PeČarić, T. Furuta, J. Mićić Hot, Y. SeO, Mond-Pečarić Method in operator inequalities, Element, Zagreb, 2005.

[15] J. G. ZHAO, J. L. Wu, Operator inequalities involving improved Young and its reverse inequalities, J. Math. Anal. Appl. 421, 2 (2015), 1779-1789. 